\title{
Adoecimento psíquico na sociedade contemporânea: notas conceituais da teoria da determinação social do processo saúde- doença
}

\author{
Mental illness on contemporary society: conceptual notes on the \\ theory of social determination of the health-disease process \\ Vitória Nassar Viapiana', Rogério Miranda Gomes², Guilherme Souza Cavalcanti de Albuquerque³
}

DOI: $10.1590 / 0103-11042018 S 414$

1 Universidade Federal do Paraná (UFPR) - Curitiba (PR), Brasil.

Orcid: https://orcid org/0000-0002-84257879

vitoriaviapiana@gmail.com

2 Universidade Federal do Paraná (UFPR), Programa de Pós-Graduação em Saúde Coletiva - Curitiba (PR), Brasil. Orcid: https://orcid. org/0000-0002-20550558

rogeriomgomes@uol.com.br

3 Universidade Federal do Paraná (UFPR), Programa de Pós-Graduação em

Saúde Coletiva - Curitiba (PR), Brasil.

Orcid: https://orcid. org/0000-0002-7544-

$412 X$

guilherme.albuquerque.

ufpr@gmail.com
RESUMO Este trabalho objetiva sistematizar elementos conceituais a fim de contribuir para a análise do adoecimento psíquico na sociedade contemporânea, a partir da teoria da determinação social do processo saúde-doença, referencial teórico que reconhece a existência de um nexo biopsíquico constituidor dos indivíduos e estabelecido em sociedade. Analisou as características do capitalismo contemporâneo, com ênfase na organização do trabalho, permeado por processos destrutivos da saúde, geradores de cargas psíquicas relacionadas com a produção de sofrimento e adoecimento. $\mathrm{O}$ desgaste gerado nesse processo produz um perfil epidemiológico marcado pelas altas taxas de transtornos mentais.

PALAVRAS-CHAVE Trabalho. Capitalismo. Estresse psicológico. Transtornos mentais. Saúde mental.

\begin{abstract}
This study's goal is to systematize conceptual elements in order to contribute to the analysis of mental illness on contemporary society, from the theory of social determination of the health-disease process, a theory that recognizes the existence of a biopsychic nexus from which are constituted individuals, and which is socially established. We analyze the characteristics of contemporary capitalism, emphasizing the organization of labor, which is teeming with processes that are destructive to health and that generate psychic loads related to the production of suffering and illness. The weariness generated in such process produces an epidemiological profile marked by high rates of mental disorders.
\end{abstract}

KEYWORDS Work. Capitalism. Stress psychological. Mental disorders. Mental health. 


\section{Introdução}

Este estudo tem como objetivo a sistematização de alguns elementos conceituais que contribuam para a análise do adoecimento psíquico na sociedade contemporânea a partir da teoria da determinação social do processo saúde-doença, tal como compreendida pela epidemiologia crítica.

Os transtornos mentais são agravos de saúde altamente prevalentes na sociedade atual. Segundo dados da Organização Mundial de Saúde (OMS)' transtornos mentais como depressão, abuso de álcool, transtorno bipolar e esquizofrenia se encontram entre as 20 principais causas de incapacidade. A OMS ${ }^{1,2}$ estima que atualmente a depressão afeta cerca de 350 milhões de pessoas, sendo que a taxa de prevalência na maioria dos países varia entre $8 \%$ e $12 \%$. É a principal causa de incapacitação dos indivíduos no mundo quando se considera o total de anos perdidos ( $8,3 \%$ dos anos para homens e $13,4 \%$ para mulheres) e a terceira principal causa da carga global de doenças em 2004. A previsão é de que subirá ao primeiro lugar até 2030.

Santos e Siqueira ${ }^{3}$ analisaram estudos sobre a prevalência de transtornos mentais na população adulta brasileira e verificaram que as taxas variam de 20 a $56 \%$. Os transtornos mais prevalentes indicados nos estudos são os de ansiedade, de humor, os somatoformes e o abuso de álcool.

Esses dados, em geral, têm como principal consequência as reivindicações por ampliação da disponibilidade de serviços de assistência aos sujeitos em sofrimento. Contudo, a gravidade do quadro tem repercutido relativamente pouco em estudos sobre as causas do aumento do adoecimento psíquico nos dias atuais, fazendo com que a relação entre sofrimento/adoecimento psíquico e condições de vida e trabalho seja ainda um tema de pouca visibilidade.

Isso se deve principalmente ao predomínio da racionalidade biomédica, a partir de meados do século XX, como principal guia orientador dos conhecimentos e práticas relacionados com o sofrimento psíquico. A moderna psiquiatria, transitando da referência na psicodinâmica para a neurobiologia, reflete esse movimento de tentativa de localização e restrição dos fenômenos psíquicos ao âmbito orgânico, cerebral. Com isso, constrói-se uma compreensão biologicista dos 'transtornos mentais' como entidades autônomas, anistóricas, isoladas do contexto sociocultural em que se inserem os indivíduos. O que Basaglia ${ }^{4}$ caracterizou como a psiquiatria colocando os sujeitos, e suas vidas, entre parênteses para compreender a doença. A partir dos anos 1950, a produção dos psicofármacos impulsiona a dinâmica biologicista por meio da teoria dos neurotransmissores. Com isso, a psiquiatria busca se aproximar da legitimidade conferida à medicina como prática social científica e supostamente neutra em relação aos processos e valores sociais ${ }^{5}$.

Esse já é, contudo, um momento de críticas às limitações da compreensão biomédica da saúde-doença, expressas nas várias teorias biopsicossociais, ecológicas e sistêmicas iniciadas no primeiro terço do século XX. Em alguns países da América Latina, esse processo ganha conotações mais críticas com a produção em torno da teoria da determinação social do processo saúde-doença que, no caso brasileiro, irá influenciar o surgimento do campo da saúde coletiva a partir do fim dos anos 1970. Esse movimento, somado a diferentes leituras críticas da área da psicologia, contribuirá para que, nas duas últimas décadas, o fenômeno do sofrimento psíquico seja objeto de estudos que problematizam sua relação com os processos sociais, com as condições de vida e de trabalho.

Ainda assim, a relação entre o adoecimento psíquico e o trabalho é pouco estudada. O fato de o sofrimento psíquico não possuir caráter tangível e ser menos visível que os agravos orgânicos dificulta o estabelecimento do chamado 'nexo causal' entre trabalho e adoecimento ${ }^{6}$.

Para Paparelli, Sato e Oliveira ${ }^{7}$ são muito comuns duas compreensões distintas acerca da relação saúde-doença e trabalho: para a primeira, a causa do adoecimento dos trabalhadores deve ser identificada no indivíduo, 
em suas características fisiológicas, psíquicas, sociais e em seu contexto de vida; a segunda defende e naturaliza a ideia de que o trabalho produz sofrimento e que isso não pode ser mudado, é uma determinação inquestionável e intransponível.

Atualmente, ampliam-se os estudos em áreas como a saúde do trabalhador e a saúde mental e trabalho que têm fornecido um rico subsídio à compreensão de processos geradores de adoecimento psíquico no trabalho. Uma característica importante desse campo de estudos da relação entre saúde mental e trabalho é a heterogeneidade conceitual e metodológica. Com a complexidade do tema, por vezes, muitos estudos utilizam-se de referenciais teóricos antagônicos, buscando no ecletismo respostas para as dificuldades de apreensão do objeto. Não obstante suas importantes contribuições, o caminho metodológico de enfoque nos fenômenos do psiquismo ocasionalmente motiva estudos com a finalidade de compreender o adoecimento psíquico relacionado com o trabalho que isola essa forma de sofrimento das demais formas de impacto do trabalho sobre a integralidade dos sujeitos. Não raramente, desconsidera-se a indissociabilidade entre os elementos do processo de trabalho que causam sofrimento psíquico e aqueles que resultam em agravos físicos. Com isso, ainda que não intencionalmente, vários desses estudos, ao fragmentar as dimensões corporal e psíquica, acabam por recair em um dualismo entre subjetividade e corpo, característico da tradição cartesiana ${ }^{8}$.

Este artigo tem o caráter de delineamento conceitual, uma aproximação ao tema, a partir da teoria da determinação social do processo saúde-doença. Utilizou-se dessa teoria, desenvolvida pela medicina social latino-americana e pela epidemiologia crítica, a fim de buscar elementos que contribuam para ampliar o conhecimento a respeito da relação entre sofrimento e trabalho. Esse referencial teórico rejeita a fragmentação entre as dimensões corporal e psíquica, reconhecendo que ambas conformam um ‘nexo biopsíquico' constituidor dos indivíduos? 9 . Esse elo biopsíquico estabelece-se em sociedade, ou seja, embora as dimensões biológica, psíquica e social componham os indivíduos, a última possui uma posição hierárquica superior na determinação dos sujeitos e coletivos humanos, inclusive em seus processos de saúde-doença, dada a sua capacidade de subsunção dos outros dois âmbitos ${ }^{10}$.

Discute-se neste escrito como as formas de produção capitalistas, permeadas por processos destrutivos da saúde física e mental, geram significativas cargas psíquicas que se relacionam com a produção de sofrimento e adoecimento. Estabeleceu-se, dessa forma, um diálogo com a profícua e contraditória produção das áreas voltadas ao estudo da relação entre sofrimento psíquico e trabalho a partir de um referencial teórico específico, procurando contribuir para o enriquecimento dos conhecimentos sobre esse tema.

\section{A determinação social do processo saúde-doença}

Para compreensão de formas particulares de sofrimento e adoecimento, como o sofrimento psíquico, é fundamental a compreensão da produção social das dimensões biológica e psíquica humanas. Isto é, os processos pelos quais as relações sociais, a história, a cultura subsumem - incluem e subordinam - o biológico. Para Breilh ${ }^{10}$, a produção de doenças ocorre no plano coletivo, e, portanto, não se pode desvincular o estudo do processo saúde-doença do contexto social em que está inserido. Para tanto, é necessário analisar os processos estruturais de cada sociedade, decorrentes de determinado grau de desenvolvimento das forças produtivas e das relações de produção. Esse complexo delimita um modo de produção específico, abrangendo determinadas classes sociais e suas frações. Nas distintas formações sociais concretas, essas classes e frações poderão apresentar novos arranjos próprios, além de segmentações em grupos e coletividades com características particulares. As classes, frações e grupos sociais 
desenvolvem determinados perfis de reprodução social, expressos em modos particulares de vida, aos quais estão associados determinados perfis epidemiológicos.

A fim de compreender a forma como se produzem esses perfis epidemiológicos, e para se contrapor à concepção biomédica tradicional de riscos e fatores, Breilh ${ }^{10}$ propõe a noção de processo, que incorpora a complexidade, contraditoriedade e movimento da realidade.

As condições de saúde-doença dos indivíduos se desenvolvem mediante um conjunto de 'processos críticos', que podem adquirir propriedades protetoras e benéficas (saudáveis) ou destrutivas e deteriorantes (insalubres) da saúde, nos vários âmbitos da vida - trabalho, consumo e cotidiano, político, ideológico e da relação com o ambiente. São 'processos críticos protetores' aqueles que favorecem defesas e suportes e estimulam uma orientação favorável à vida humana. Já os 'processos críticos destrutivos' geram privação ou deterioração da vida. Os processos se desenvolvem no seio de uma formação social específica e são marcados pelas possibilidades reais de cada modo de vida e, portanto, podem se tornar protetores ou destrutivos de acordo com as condições históricas em que ocorrem. Não existem processos protetores ou destrutivos de forma abstrata. É no seu desenvolvimento concreto que os processos adquirem caráter protetor ou destrutivo. Um mesmo processo pode ainda desencadear simultaneamente efeitos protetores e destrutivos ${ }^{10}$.

Grande parte dos processos protetores e destrutivos resulta, direta ou indiretamente, das formas como se organiza o processo de trabalho, pois é ele o aspecto determinante das condições de vida e em torno do qual se estrutura um modo de produção"1. A cada modo de produção correspondem processos de trabalho específicos. Para Laurell e Noriega9, a conformação concreta do trabalho permite compreender como se constitui o nexo biopsíquico humano. Todavia, não é suficiente analisar apenas os aspectos técnicos do trabalho, como suas características físicas, químicas e mecânicas ou os instrumentos e tecnologias nele envolvidos. Deve-se compreender o processo de trabalho, no caso do capitalismo, como a materialização de uma determinada relação de exploração do capital sobre o trabalho.

Buscando apreender a complexidade do nexo biopsíquico humano, sem reduzi-lo a elementos isolados, a medicina social latino-americana desenvolveu a categoria 'cargas de trabalho', possibilitando a identificação de elementos do processo de trabalho que interatuam dinamicamente entre si e com o corpo-psiquismo do trabalhador, gerando desgaste (perda da capacidade potencial e/ ou efetiva corporal e psíquica). As cargas são expressões particulares das formas específicas do processo de produção e podem ser divididas em físicas, químicas, biológicas, mecânicas, fisiológicas e psíquicas. Ao atuarem sobre o corpo-psiquismo, combinam-se, potencializam-se umas às outras e se tornam processos intracorporais e intrapsíquicos complexos, provocando mudanças fisiológicas?.

Mesmo as cargas físicas, químicas, mecânicas e biológicas podem ter efeitos psíquicos nos trabalhadores a elas submetidos, como afirma Seligmann-Silva ${ }^{\mathbf{1 2}}$ ao se referir a questões como ruído, calor, poeira, vibrações, gases, ventilação e luminosidade.

No que se refere especificamente às cargas psíquicas, são divididas em elementos que causam sobrecarga psíquica (tensão prolongada) e subcarga (impossibilidade de desenvolvimento e uso da capacidade psíquica). Como exemplos de sobrecarga psíquica, podem-se citar a atenção permanente, a supervisão com pressão, a consciência da periculosidade do trabalho e os altos ritmos de trabalho. A subcarga psíquica pode ser exemplificada pela perda do controle sobre o trabalho quando o trabalhador é subordinado ao movimento de uma máquina, a desqualificação do trabalho advinda da separação entre concepção e execução, a fragmentação do processo de trabalho, a repetitividade, monotonia, entre outros. Tanto as sobrecargas quanto as subcargas psíquicas são comuns sob o modo de produção capitalista? . 
Os processos críticos implicam a modulação de cargas de trabalho e, ao mesmo tempo, configuram-se como uma síntese concreta destas. Por exemplo, a intensificação do trabalho é um processo crítico destrutivo, que tem como consequência a intensificação das cargas existentes em um processo de trabalho particular. Nesse sentido, compreende-se o processo de trabalho como constituído por múltiplos processos que, por sua vez, resultam na alteração de diferentes cargas.

Dessa forma, o estudo de determinada condição de saúde-doença envolve a análise de processos estruturais do modo de produção predominante em dada formação social. Neste caso, essa investigação implica a análise do capitalismo contemporâneo e suas características fundamentais determinantes dos atuais processos de trabalho. Só assim é possível apreender em profundidade o perfil epidemiológico da sociedade contemporânea, marcado pelas altas taxas de sofrimento e de adoecimento psíquico.

\section{Trabalho, subjetividade e capitalismo}

A centralidade do trabalho na vida dos indivíduos não se deve somente ao fato, importante, de ocupar parte significativa do tempo de vida na sociabilidade contemporânea. Por meio do trabalho em sociedade, o humano produz os meios necessários à sua sobrevivência, ampliando as capacidades humanas de transformação da natureza e do mundo. Ao transformar o mundo, os sujeitos também transformam a si próprios; a atividade é a base dos atributos humanos. Nesse sentido, o trabalho tem um caráter ontológico, constituidor do ser social, e fundador, portanto do gênero humano"1.

Além de ser o meio para a satisfação das necessidades pessoais, o trabalho é também fonte de identificação e autoestima, de desenvolvimento das potencialidades humanas e de sentimento de participação nos objetivos da sociedade ${ }^{\mathbf{1 3}}$. A centralidade do trabalho, portanto, não decorre apenas de seu papel como fonte de sustento para a maioria da população, mas também de seu caráter constituidor dos sujeitos, inclusive na dimensão psíquica. Como atividade principal do gênero humano, ela engendra processos de formação da consciência e da personalidade, bem como desperta emoções e sentimentos, elementos envolvidos com o sofrimento e com o adoecimento psíquico.

A própria estrutura da consciência e a personalidade estão intimamente relacionadas com a atividade, visto que são resultado da relação entre fatores extrínsecos, as condições materiais de vida e as relações sociais, e fatores intrínsecos, os processos biológicos e psíquicos que se desenvolvem em consequência da atividade humana ${ }^{\mathbf{1 4}}$. Desse modo, essas duas dimensões são sínteses de aspectos objetivos e subjetivos, sendo formadas a partir das relações sociais que o indivíduo estabelece com o mundo, por meio de sua atividade ${ }^{15}$.

Emoções e sentimentos também estão intimamente relacionados com as atividades que os indivíduos desempenham, incluindo o trabalho, pois são originados na realidade objetiva.

O sujeito tem uma atitude emocional em relação aos objetos e fenômenos do 'mundo real' e os sente de distinta maneira segundo as relações objetivas particulares em que se encontra com eles ${ }^{16}$ [grifo e tradução nossa].

Reações emocionais são motivadas por tudo o que, direta ou indiretamente, satisfaz necessidades dos indivíduos e que se relaciona com as exigências sociais. Objetos e fenômenos que permitem a satisfação das necessidades ou correspondem às exigências sociais suscitam vivências emocionais positivas. Por outro lado, aquilo que obstrui a satisfação de necessidades ou não se adequa às exigências da sociedade resulta em emoções negativas.

Para Leontiev ${ }^{\mathbf{1 4}}$, um dos principais componentes da estrutura da consciência é a relação entre significações sociais e sentidos pessoais. A significação é o reflexo generalizado da realidade elaborado pela humanidade e fixado na forma 
de conceitos, saberes ou até mesmo saber-fazer (modo de ação generalizado, normas de comportamentos etc.). É a forma ideal da experiência e da prática sociais da humanidade, a forma mediante a qual o homem assimila a experiência humanageneralizada. É independente da relação individual com a realidade refletida. O que uma significação se torna para determinado indivíduo constitui o sentido subjetivo e pessoal. O sentido traduz a relação do sujeito com os fenômenos objetivos conscientizados e está diretamente vinculado à sua vida, suas necessidades e interesses.

Sob o capitalismo, o trabalhador é alienado em relação aos meios de trabalho, perdendo o controle sobre o objeto, os instrumentos e a organização do trabalho. Com isso, além dos produtos, o próprio processo de trabalho aparecerá para os agentes como externo e independente, um ente estranho. Produto e processo de trabalho, uma vez reificados, ao invés de controlados pelos agentes, aparecem como um poder que lhes é superior, que lhes controla. O trabalho, ao invés de espaço de realização, de finalidade da existência humana, torna-se, para os agentes, mero meio de garantia da sobrevivência individual ${ }^{11}$. O sentido do trabalho para os trabalhadores deixa de se localizar nele mesmo, encontrando-se em algo externo - o salário. Em outras palavras, o sentido que o trabalho adquire para o trabalhador não coincide com sua significação objetiva, há uma cisão entre sentido e significado. Essa relação se traduz, na consciência, pela desintegração de sua estrutura geral ${ }^{14}$. Nesse contexto, o trabalho perde sua capacidade realizadora dos sujeitos, agrega cada vez menos elementos que dão sentido à sua vida, podendo se converter facilmente em trabalho imposto, forçado e, consequentemente, fonte de sofrimento.

\section{Capitalismo contemporâneo e acumulação flexível}

Embora a hegemonia mundial do modo de produção capitalista permaneça praticamente inabalável, as formas como se apresenta a organização dos processos produtivos têm sofrido modificações, reestruturações periódicas, associadas às necessidades de cada fase da acumulação.

A partir da década de 1970, em resposta a mais uma de suas crises, o capital empreende uma reorganização da produção e do trabalho visando à recuperação das taxas de lucro e dos níveis de expansão. Essa reestruturação produtiva institui um conjunto de processos que representa a passagem a um novo regime de acumulação, caracterizado pela busca da superação do caráter mais rígido do fordismo-taylorismo, anteriormente predominante. A 'acumulação flexível', originalmente desenvolvida a partir do modelo toyotista, apoia-se na flexibilidade dos processos e mercados de trabalho, e dos produtos e padrões de consumo ${ }^{17}$. A maior flexibilidade e mobilidade permite aos empregadores exercerem maior controle sobre a força de trabalho, já enfraquecida pelo aumento do desemprego a níveis sem precedentes após a Segunda Guerra Mundial.

Em resposta à dinamicidade do mercado consumidor, o toyotismo diferencia-se da produção homogênea característica do modelo fordista-taylorista incorporando a variedade e a heterogeneidade. Baseada no trabalho em equipe e integrando a multivariedade de funções, confere nova aparência ao trabalho parcelar. A produção é estruturada de forma flexível, possibilitando ao trabalhador operar várias máquinas simultaneamente, sob o princípio do just in time, para o melhor aproveitamento possível do tempo de produção ${ }^{\mathbf{1 8}}$.

Além disso, nesta fase da acumulação capitalista, as empresas se tornam mais 'enxutas', isto é, reduzem o contingente de força de trabalho (trabalho vivo) ao mesmo tempo que ampliam a tecnologia (trabalho morto) com os recursos da automação e da microeletrônica. A introdução de novas tecnologias é um dos aspectos centrais da acumulação flexível e tem como resultado, para um segmento dos trabalhadores, a exigência de maior qualificação, bem como a capacidade de realizar múltiplas atividades simultaneamente. Essa 
'multifuncionalidade' do trabalhador, contudo, diferentemente de significar ampliação do grau de reflexão e realização no trabalho, reflete de fato a intensificação dos ritmos e cargas de trabalho ${ }^{\mathbf{1 8}}$. Nesse sentido, talvez o termo que melhor expresse essa nova condição posta para o trabalhador contemporâneo seja o de multitarefas, dada a característica de responsabilização por múltiplos atos fragmentados.

Por outro lado, a maioria das atividades são cada vez mais simplificadas, empregando uma força de trabalho com baixo grau de qualificação e substituível a qualquer momento. Como consequência, tem-se, de um lado, uma parte mais qualificada dos trabalhadores, com algumas condições mínimas de segurança no emprego, e, de outro, uma grande parcela de trabalhadores precarizados.

Também faz parte da atual tendência do mercado a redução do número de trabalhadores em tempo integral, com vínculos mais estáveis com o emprego, e a contratação de uma força de trabalho 'flexível', subcontratada, facilmente empregada e demitida ${ }^{17}$. Ampliamse as formas precárias de emprego - trabalho informal, terceirizado, em tempo parcial - com menos direitos sociais. $\mathrm{O}$ aumento das taxas de desemprego e a transformação do desemprego maciço em fenômeno permanente resultam em um quadro extremamente precário e de pauperização, inclusive com utilização de mecanismos supostamente pretéritos de exploração - aumento de jornadas, trabalho infantil, trabalho escravo ou semiescravo ${ }^{19}$.

Com a acumulação flexível, torna-se cada vez mais comum a utilização de formas de gestão e técnicas de trabalho em equipe (células de produção, times de trabalho, grupos semiautônomos) que exigem o envolvimento participativo dos trabalhadores. Requer-se uma nova disposição subjetiva, uma mudança de atitude em relação ao processo produtivo, incentivando-se habilidades cognitivo-comportamentais proativas, mobilizando-se conhecimentos, capacidades, atitudes e valores, para que os trabalhadores se adaptem à nova organização do trabalho de modo favorável à acumulação capitalista 20 . Com essa 'captura da subjetividade', reprime-se e controla-se a força de trabalho mediante a internalização de regras, utilizando as emoções dos agentes e constituindo um processo de cooperação/ cooptação, de envolvimento manipulatório ${ }^{21}$. Como consequência, fragmenta-se a consciência de classe dos trabalhadores, enfraquecendo sua luta contra o capital18.

Além das técnicas de envolvimento, com o impulso à intensificação do trabalho, estabelecem-se novas formas de coerção, mais refinadas, veladas e associadas à busca de consentimento (cooptação) dos trabalhadores. Generalizam-se formas de violência, como o assédio, dispositivos organizacionais voltados à obtenção de submissão dos trabalhadores às imposições de sobrecarga de trabalho, uma forma política repressiva escolhida pelas empresas para viabilizar a lucratividade ${ }^{22}$.

Com a acumulação flexível, o trabalho expande-se para além da empresa, absorvendo outras dimensões do cotidiano, como os espaços de lazer e descanso, tornando praticamente todo o tempo de vida extensão do trabalho ${ }^{20}$. Com as novas tecnologias de comunicação, o espaço das empresas se 'desterritorializa', de modo que tarefas do trabalho invadem a esfera doméstica, estendendo a jornada. $\mathrm{O}$ trabalhador deve estar a todo momento 'conectado', psiquicamente disponível para a empresa, podendo ser solicitado a qualquer momento, de acordo com a demanda de produção ${ }^{\mathbf{2 1}}$. Além disso, parte importante do tempo livre destina-se ao aperfeiçoamento profissional, qualificação e adequação ao processo de trabalho. Esse quadro, além de contribuir para ampliação do desgaste, impacta, ainda, na redução do tempo de recuperação, de reprodução da força de trabalho ${ }^{8}$.

Todas essas transformações particulares da acumulação flexível, cabe salientar, respondem a uma necessidade imanente ao modo de produção capitalista, independentemente da formação social concreta em que se apresente: a busca permanente pelo aumento da acumulação. Como a base material da acumulação 
de valor é a exploração do trabalho, trata-se de ampliar a taxa de mais-valia. Seja através dos mecanismos de aumento da mais-valia absoluta - aumento de jornada, intensificação do trabalho, redução de salários; seja mediante mecanismos de aumento da mais-valia relativa - aumento da produtividade por meio de avanço tecnológico. Esse quadro alarmante tem como importantes repercussões a desregulamentação dos direitos trabalhistas, o aumento da fragmentação entre os trabalhadores, a precarização e terceirização da força de trabalho e a subordinação do sindicalismo classista ${ }^{18}$.

\section{Algumas implicações do trabalho na sociedade contemporânea sobre $o$ psiquismo}

Esse quadro sintético da acumulação flexível pode subsidiar a compreensão de várias repercussões sobre a saúde dos indivíduos e coletividades nos dias atuais. São vários os 'processos críticos destrutivos' nos atuais processos de trabalho. Dentre os principais, cabe destacar: o aumento de jornada; os vários mecanismos de intensificação do trabalho (aumento de ritmo, a multifuncionalidade, o aumento das formas de salário por peça-produtividade, a implantação de metas, o trabalho em domicílio, entre outros); as várias formas de precarização (terceirização, trabalho temporário, parcial etc.); as novas formas de coerção (violência-assédio); os atuais mecanismos de controle e consentimento (a captura da subjetividade, o autocontrole pela equipe-célula produtiva).

Esses processos serão responsáveis por produzir o aumento de um conjunto de cargas específicas - mecânicas, físicas, psíquicas, fisiológicas etc. - a depender da atividade laboral particular analisada. $\mathrm{O}$ aumento do desgaste provocado por essas cargas ante as limitadas possibilidades de restauração das capacidades vitais dos sujeitos produzirá um perfil epidemiológico típico desse período.
A superioridade do desgaste sobre a reprodução pode se manifestar física e/ou psicologicamente de diversas formas. Por um lado, além da manutenção dos acidentes de trabalho (traumatismos, amputações e mortes), ampliam-se as doenças crônicas relacionadas com o aumento de ritmo e de pressão, sejam as lesões musculares (lesões por esforços repetitivos, lombalgias crônicas etc.), sejam as doenças cardiovasculares, que, apesar de associadas em estudos epidemiológicos a condições de trabalho sob estresse excessivo, têm o nexo com o trabalho cotidianamente ignorado ${ }^{\mathbf{1 9}, 23}$.

Em relação ao desgaste psíquico, como consequência das novas formas de gestão do trabalho, ocorre o aumento das sobrecargas psíquicas, tais como: a pressão por intermédio de metas, ou mesmo dos próprios colegas de trabalho; a 'internalização' das regras da empresa por parte dos trabalhadores; a exigência de alta produtividade e a atenção permanente dela decorrente; a concentração exigida pelo aumento do número de máquinas a serem operadas ou supervisionadas; e os altos ritmos de trabalho, nos quais se eliminam quaisquer períodos de suposta 'improdutividade' (momentos de descanso). Paralelamente, acentuam-se as subcargas psíquicas, com a restrição do desenvolvimento das capacidades psíquicas em função do aprofundamento da alienação, tal como se observa na subordinação dos indivíduos à tecnologia cada vez mais automatizada, na manutenção do trabalho parcelar, ainda que no formato multitarefas, e na ausência de interferência dos trabalhadores sobre o planejamento do trabalho ${ }^{8}$.

Os estudos de Seligmann-Silva ${ }^{12}$ atestam para o fato de que a intensificação do trabalho é um dos principais fatores na produção do cansaço e de suas complicações sobre a saúde mental. De acordo com a autora, as manifestações mais comuns são: a fadiga, sentida pelos trabalhadores como cansaço e irritabilidade, expressando-se também em desânimo e descontrole, podendo evoluir para a fadiga patológica e o Esgotamento Profissional (Síndrome de Burnout); os distúrbios do sono, 
cuja acentuação contribui para o agravamento da fadiga e para o surgimento de quadros psicopatológicos; o desencadeamento de crises (psicóticas, epilépticas, de agitação psicomotora etc.), causadas principalmente por situações de aumento extremo da jornada de trabalho (prolongamento da jornada, supressão de folgas, dobras de turno, trabalho em domicílio) e pela intensificação do ritmo de produção; os acidentes de trabalho (o desgaste gerado no trabalho pode prejudicar a atenção, memória, raciocínio e a capacidade de tomar decisões rapidamente em situações emergenciais, o que pode contribuir para ocasionar acidentes); e os transtornos mentais.

Em época de acumulação flexível, os mecanismos de intensificação do trabalho se aprimoram. O capital torna-se capaz de mobilizar, intensa e profundamente, a subjetividade, estimulando o comprometimento dos trabalhadores pela vigilância coletivamente exercida pela equipe ${ }^{20}$. Essa forma de controle, exercida pelos trabalhadores sobre si mesmos, gera insegurança, nervosismo, ansiedade, perturbações no sono e sintomas psicossomáticos. O ambiente de trabalho se torna mais competitivo, e as relações de trabalho, mais distantes e frias, permeadas pela individualidade e desconfiança. Além disso, as formas de violência, como o assédio, ampliam a instabilidade e tensões no local de trabalho, transformando-o em um espaço degradado, inseguro e arriscado, não só para os que sofrem o abuso, mas para todos ${ }^{22}$.

Para Seligmann-Silva ${ }^{\mathbf{1 2}}$, somam-se a esse quadro de tensão emocional as vivências de insegurança no trabalho. Trabalhadores mais vulneráveis, como os temporários, ainda sofrem pela situação de desproteção ou de alternância entre emprego e desemprego, o que pode gerar ansiedade e levar a transtornos mentais.

Os altos níveis de desemprego e a permanência de um significativo exército industrial de reserva exercem forte coerção sobre os trabalhadores empregados, fazendo com que se submetam a condições precárias de trabalho, na tentativa de manterem o emprego. Configura-se um cenário em que o trabalho gera altos níveis de desgaste ao nexo biopsíquico humano, prolongando as circunstâncias desgastantes até o esgotamento ou adoecimento ${ }^{23}$.

Aos desempregados, ainda, são comuns sentimentos de vergonha, autodesvalorização, insegurança e tristeza pelas perdas de emprego, além de revolta e injustiça. Isso contribui para a irradiação de uma sensação generalizada de instabilidade, desenvolvida inclusive pelos trabalhadores inseridos no mercado formal de trabalho. Uma consequência imediata do desemprego é o isolamento social, podendo ocasionar quadros psicopatológicos, sendo o alcoolismo e a depressão os mais referidos na literatura ${ }^{12}$.

Diretamente relacionado com a problemática do sofrimento psíquico no trabalho está o tema do suicídio. Observou-se que, segundo Fried $^{\mathbf{1 2}}$, durante crises econômicas, ocorre considerável aumento dos índices de suicídio e das taxas de transtornos mentais, além do crescimento de problemas psicossomáticos. Reeves, McKee e Stuckler ${ }^{\mathbf{2 4}}$ verificaram que, após a recessão de 2007, as taxas de suicídio aumentaram em quase todos os países da Europa. Segundo os autores, choques econômicos podem piorar a saúde mental e levar ao suicídio, principalmente devido ao desemprego (o suicídio é 2,5 vezes mais comum em desempregados) e ao endividamento.

Segundo Franco, Druck e SeligmannSilva ${ }^{25}$, muitos dos regimes de trabalho atuais estão em contradição com os biorritmos dos indivíduos, principalmente no que se refere às cargas e ritmos de trabalho, resultando em adoecimentos. De fato, a fase da acumulação flexível coloca exigências ao nexo biopsíquico geradoras de níveis de desgaste que superam significativamente sua capacidade de reprodução. Se em momentos pretéritos, como os séculos XVIII e XIX, a disparidade entre desgaste e reprodução tinha como consequência a alta mortalidade e baixa expectativa de vida da classe trabalhadora, nos dias atuais, esse contraste se expressa de forma distinta. Reduz-se a mortalidade e prolonga-se a vida. Entretanto, uma vida sofrida, agonizante, permeada por 
profundos sinais de desgaste, expressos nas diversas formas de sofrimento crônico.

\section{Considerações finais}

Discutiu-se neste trabalho como as características gerais do modo de produção capitalista, e seus aspectos mais específicos desenvolvidos a partir da acumulação flexível, podem afetar a subjetividade, engendrando emoções e sentimentos relacionados com processos de sofrimento e de adoecimento psíquico. Essa dinâmica pode ser compreendida a partir dos conceitos de processos críticos - protetores e destrutivos - e de cargas de trabalho, os quais possibilitam a compreensão do desgaste que é gerado no processo de trabalho, bem como a conformação do nexo biopsíquico humano nesse contexto.

O enfoque do artigo no processo de trabalho decorre das limitações de espaço e não implica a desconsideração de outros âmbitos da vida dos indivíduos e coletividades permeados por processos críticos protetores e destrutivos da saúde, como os âmbitos do cotidiano e do consumo, o político-ideológico e o do ambiente. Ao mesmo tempo, cabe destacar o papel condicionante do trabalho sobre essas outras dimensões.

Práticas de prevenção relacionadas com o sofrimento psíquico devem necessariamente ter como objetivo a transformação desses processos, sob pena de perderem eficiência em produzir alteração significativa nos indicadores epidemiológicos.

Nesse sentido, são fundamentais as iniciativas voltadas à melhoria das condições de trabalho, redução da intensificação, dos ritmos, da precarização e da violência no trabalho por exemplo. Como o principal processo geral motivador das várias organizações e estruturas produtivas na sociedade é a acumulação capitalista, o processo saúde-doença na sociedade reflete inevitavelmente a contradição capital-trabalho. Transformar os processos de trabalho - e, por consequência, a sociedade - em espaços mais saudáveis e realizadores para seus executores envolve necessariamente a contraposição à lógica do capital. Trata-se, em síntese, de colocar a vida e a saúde acima do lucro.

\section{Colaboradores}

Vitória Nassar Viapiana contribuiu para a concepção, planejamento, análise e elaboração do texto. Rogério Miranda Gomes contribuiu para a concepção, planejamento, análise e elaboração do texto. Guilherme Souza Cavalcanti de Albuquerque contribuiu para a revisão do conteúdo. 


\section{Referências}

1. World Health Organization. The global burden of disease: 2004 update [Internet]. Geneva: WHO, 2008 [acesso em 2017 maio 21]. Disponível em: http://www. who.int/healthinfo/global_burden_disease/GBD_ report_2004update_full.pdf.

2. World Health Organization. Mental health action plan 2013-2020 [Internet]. Geneva: WHO, 2012 [acesso em 2017 maio 21]. Disponível em: http://apps.who. int/iris/bitstream/10665/89966/1/9789241506021_ eng.pdf?ua=1.

3. Santos EG, Siqueira MM. Prevalência dos transtornos mentais na população adulta brasileira: uma revisão sistemática de 1997 a 2009. J Bras Psiquiatr. 2010 59(3):238-246.

4. Basaglia F. Loucura/delírio. In: Basaglia F. Escritos selecionados em saúde mental e reforma psiquiátrica. Rio de Janeiro: Garamond; 2005. p. 237-257.

5. Caponi S. Uma análise epistemológica do diagnóstico de depressão. Cad Bras Saúde Mental. 2009 1(1):1-8.

6. Borsoi ICF. Da relação entre trabalho e saúde à relação entre trabalho e saúde mental. Psicol Soc. 2007; 19(1):103-111.

7. Paparelli R, Sato L, Oliveira F. A saúde mental relacionada ao trabalho e os desafios aos profissionais de saúde. Rev Bras Saúde Ocup. 2011; 36(123):118-127.

8. Malaguty S. Sofrimento pelo trabalho: uma contribuição a partir da Teoria da Atividade de A. N. Leontiev [tese]. [Curitiba]: Universidade Federal do Paraná; 2013. 151 p.

9. Laurell AC, Noriega M. Processo de produção e saúde: trabalho e desgaste operário. São Paulo: Hucitec; 1989.

10. Breilh J. Epidemiologia crítica: ciência emancipadora e interculturalidade. Rio de Janeiro: Fiocruz; 2006.
11. Lukács G. Para uma ontologia do ser social I. São Paulo: Boitempo; 2012.

12. Seligmann-Silva, E. Trabalho e desgaste mental: o direito de ser dono de si mesmo. São Paulo: Cortez; 2011.

13. Navarro VL, Padilha, V. Dilemas do trabalho no capitalismo contemporâneo. Psicol Soc. 2007; 19(1):1420.

14. Leontiev A. O desenvolvimento do psiquismo. São Paulo: Moraes; 1998.

15. Martins LM. A formação social da personalidade do professor: um enfoque vigotskiano. Campinas: Autores Associados; 2007.

16. Smirnov AA, Leontiev AN, Rubinshtein SL, et al. Psicologia. México: Grijalbo; 1960. Blagonadezhina LV. Las emociones y los sentimentos. p. 355-384.

17. Harvey D. Condição pós-moderna: uma pesquisa sobre as origens da mudança cultural. São Paulo: Loyola; 2003.

18. Antunes R. Os sentidos do trabalho: ensaio sobre a afirmação e a negação do trabalho. 2. ed. São Paulo: Boitempo; 2013.

19. Lacaz FAC. Qualidade de vida no trabalho e saúde-doença. Ciênc Saúde Coletiva. 2000; 5(1):151-161.

20. Alves G. Trabalho e subjetividade: o espírito do toyotismo na era do capitalismo manipulatório. São Paulo: Boitempo; 2011.

21. Souza TMS. Assédio moral e reestruturação produtiva. Rev Trabajo Social. 2009 2(2):21-36.

22. Barreto M, Heloani R. Violência, saúde e trabalho: a intolerância e o assédio moral nas relações laborais. Serv Soc Soc. 2015; (123):544-561. 
23. Almeida MR, Gomes RM. Medicalização social e educação: contribuições da teoria da determinação social do processo saúde-doença. Nuances. 2014 jan; 25(1):155-175.

24. Reeves A, Mckee M, Stuckler D. Economic suicides in the Great Recession in Europe and North America. Br J Psychiatry. 2014; 205(3):246-247.
25. Franco T, Druck G, Seligmann-Silva E. As novas relações de trabalho, o desgaste mental do trabalhador e os transtornos mentais no trabalho precarizado. Rev Bras Saúde Ocup. 2010; 35(122):229-248.

Recebido em 18/06/2017

Aprovado em 05/01/2018

Conflito de interesses: inexistente

Suporte financeiro: não houve 